\title{
Characterization of Togolese Gneisses and Granites by Rock Drilling Test
}

\author{
Pachoukova Irina*, Ayite Yawovi Mawuénya Xolali Dany, Bedja Koffi-Sa \\ Research Team in Engineering Sciences, Civil Engineering Department, Higher National Engineers School, University of Lomé, Lomé, Togo \\ Email address: \\ pachoukova@yahoo.fr (P. Irina), danyayite@gmail.com (A. Y. M. X. Dany), bedjaeugene@gmail.com (B. Koffi-Sa) \\ ${ }^{*}$ Corresponding author
}

\section{To cite this article:}

Pachoukova Irina, Ayite Yawovi Mawuénya Xolali Dany, Bedja Koffi-Sa. Characterization of Togolese Gneisses and Granites by Rock Drilling Test. International Journal of Materials Science and Applications. Vol. 6, No. 6, 2017, pp. 316-324.

doi: 10.11648/j.ijmsa.20170606.18

Received: November 22, 2017; Accepted: December 4, 2017; Published: December 27, 2017

\begin{abstract}
This paper introduces the study of Togolese gneiss and granites' intrinsic properties such as mineralogical composition, density, porosity, homogeneity one the one hand, and their mechanical properties such as resistance to attrition, abrasion and puncturing depth on the other. After the correlation analysis, significant correlations between the mechanical properties of the rocks (Los Angeles and Micro-Deval) and the depth of perforation obtained by the rock drilling test were found, as well as the not significant correlations between the mineralogical composition and the physical properties of the rock were observed. Laboratories test often performed to obtain Los Angeles and Micro-Deval values are expensive and time consuming. For this, the depths (parallel and perpendicular to the foliation planes for the gneisses or two perpendicular planes for the granites) obtained during a rock drilling test will be used to estimate its coefficients (Los Angeles and Micro-Deval). This study, is based on a database of a sample size of 32 to determine the parameters of the multifactorial model of size 6 used for the validation tests.
\end{abstract}

Keywords: Mineralogical Composition, Density, Porosity, Homogeneity, Mechanical Properties, Rock Drilling Test, Models

\section{Introduction}

A longstanding a construction begins with the use of materials (sands, fine gravels, stones) coming from good quality natural rocks used as such or crushed. The aggregates are the prevalent materials composing the bed, base and surface course of roads, and are also used in fabricating concrete and mortar cement. The durability of the quality of these bases under the influence of the traffics depends on their mechanical and physical properties.

The principal specification for the use of the aggregates relates to their mechanical resistance: they must possess sufficient hardness to resist deterioration and fragmentation in consequence of load application. This is crucial because once in use these aggregates will be bound together, either by a hydraulic binder in the case of Portland cement concrete, either by a bitumen binder in the case of asphaltic concretes, or by forces of friction created by compaction in the case of road aggregates.
Currently in Togo, the aggregates most used in civil engineering come from the gneisses and the granites originating from careers used for industrial production and which function permanently, or from old careers exploited by the local population.

The current tests used to evaluate the quality and durability of these aggregates are expensive, complex and long in procedure, especially when installation of new production units is involved.

The intrinsic characteristics, such as the mineralogical composition, the porosity, the density and the homogeneity of the gneisses and the granites have been studied and their influence on the mechanical properties of the aggregates resulting from these rocks has been demonstrated $[1,2,3,4]$. The drillability test was used, for example in the characterization of limestones [5] and the statistics prove the correlation between the properties of the rocks and their drillability [6]. Several 
authors have proposed methods of predicting the rock drillibility based on cognitive systems of comparative or neural networks and wear factor using engineering properties of rocks analysis [7] and drilling rate (DR) using the rock mass drillability index (RDi) involved the intact rock mechanical properties structural properties of rock masses [8] but also many parameters including rock properties, machine parameters of the chosen rig and the working process [9].

In the attempt to reduce the rather high costs of traditional tests, we propose an approach based on drillability tests which would enable to determine the mechanical properties of the aggregates used in civil engineering in Togo.

\section{Material and Methods}

\subsection{Characteristics of the Rocks}

The aims are, first to determine a correlation between the rock drillability and the characteristics of the sampled gneisses and granites; and second, to construct models of rock drillability according to the mechanical and physical properties, particularly the rock's resistance to abrasion by Los Angeles, resistance to attrition by Micro-Deval, its porosity, homogeneity and density.

Table 1. Characteristics of the gneisses and the granites.

\begin{tabular}{|c|c|c|c|c|c|c|c|c|c|}
\hline Echantillon & rock & Texture & LA & MD & Density & Homogeneity & Porosity, \% & Quartz,\% & Biotite, $\%$ \\
\hline $\mathrm{K} 1$ & ga & Foliation clear & 18 & 6,0 & 4,44 & 3,24 & 0,41 & 12,5 & 2,4 \\
\hline St & gr & Equante & 22 & 8,2 & 2,53 & 0,992 & 2,06 & 10,6 & 4,2 \\
\hline $\mathrm{Km} 1$ & gg & Foliation clear & 19 & 6,6 & 2,99 & 2,811 & 0,50 & 59,2 & 4,4 \\
\hline D1 & gr & Equante & 22 & 8,2 & 2,52 & 3,2 & 0,41 & 23,8 & 8,1 \\
\hline Ls2 & gg & Foliation clear & 26 & 10,5 & 3,3 & 2,009 & 0,79 & 46,7 & 0,2 \\
\hline Ls1 & gg & Foliation clear & 26 & 10,5 & 3,63 & 0,743 & 2,46 & 42,7 & 0,8 \\
\hline Gk1 & $\mathrm{gb}$ & Foliation clear & 26,7 & 10,9 & 2,87 & 0,563 & 4,45 & 11,1 & 10,1 \\
\hline Kpl & gba & Foliation frustrates & 29,8 & 12,6 & 2,25 & 1,16 & 1,67 & 7 & 4,9 \\
\hline R1 & $\mathrm{gba}$ & Foliation frustrates & 30 & 12,7 & 3,2 & 0,436 & 3,92 & 5,6 & 6,9 \\
\hline Gl1 & gba & Foliation frustrates & 38,7 & 17,6 & 3,44 & 0,654 & 3,63 & 5,4 & 10,6 \\
\hline Wn1 & gba & Foliation frustrates & 44,5 & 20,8 & 3,08 & 0,666 & 3,54 & 5,8 & 10 \\
\hline $\mathrm{Ng} 4$ & gr & Equante & 26 & 10,5 & 2,53 & 1,21 & 1,57 & 6,8 & 2,9 \\
\hline Li 5 & gba & Foliation clear & 31,5 & 13,6 & 3,6 & 0,922 & 2,28 & 6,5 & 15,2 \\
\hline Gli2 & gba & Foliation & 28,7 & 11,4 & 2,87 & 0,604 & 4,26 & 10,3 & 22,1 \\
\hline B1 & $\mathrm{gb}$ & Foliation clear & 26 & 10,0 & 3,08 & 1,316 & 2,63 & 15 & 18,4 \\
\hline $\mathrm{Ag} 4$ & gab & Foliation & 41,5 & 17,8 & 3,01 & 0,983 & 1,09 & 3,2 & 11,1 \\
\hline Ag6 & gab & Foliation & 33,8 & 13,6 & 3,21 & 0,597 & 3,82 & 4,8 & 7,8 \\
\hline L3 & gbag & Foliation clear & 27,6 & 11,0 & 3,8 & 0,729 & 3,94 & 9,9 & 22,1 \\
\hline Gk2 & $\mathrm{gb}$ & Foliation & 26,7 & 10,4 & 2,87 & 0,563 & 4,63 & 11,1 & 10,1 \\
\hline Kp3 & $\mathrm{gb}$ & Mylonitique & 20,7 & 8,7 & 2,91 & 1,0295 & 1,21 & 38,9 & 15,2 \\
\hline R6 & $\mathrm{gb}$ & Foliation clear & 26 & 13,3 & 2,85 & 0,548 & 1,5 & 7,7 & 13,1 \\
\hline Gli3 & $\mathrm{gb}$ & Foliée & 30 & 9,2 & 3,025 & 0,494 & 4,38 & 17 & 28.5 \\
\hline R4 & $\mathrm{gb}$ & Foliée & 24,7 & 9,2 & 2,35 & 0,343 & 1,51 & 14,7 & 16,5 \\
\hline Gl2 & gba & Foliation frustrates & 38,7 & 16,2 & 3,44 & 0,654 & 6,5 & 5,4 & 10,6 \\
\hline $\mathrm{Nd} 3$ & gr & équante & 25.9 & 9.8 & 3.02 & 1.143 & 1.63 & 5.2 & 5.4 \\
\hline $\mathrm{Nb} 1$ & gr & équante & 26 & 8.2 & 2.79 & 0.287 & 5.153 & 5.1 & 0.0 \\
\hline $\mathrm{Nd} 1$ & gr & équante & 28 & 12.2 & 3.68 & 0.338 & 4.91 & 7.0 & 2.0 \\
\hline $\mathrm{F} 2$ & ga & Foliation clear & 23 & 7.9 & 2.81 & 3.2 & 0.324 & 11.2 & 0.0 \\
\hline Ng6 & gr & équante & 28 & 12.2 & 2.4 & 0.621 & 3.752 & 6.7 & 2.5 \\
\hline $\mathrm{Ng} 10$ & gr & équante & 28 & 12 & 2.68 & 0.523 & 4.118 & 7.0 & 4.5 \\
\hline
\end{tabular}

$\mathrm{ga}=$ gneiss with amphibole

$\mathrm{gb}=$ gneiss with biotite

gba=gneiss with biotite and amphibole

gab=gneiss with amphibole and biotite

gr=granite

gg=granulite with garnet

gbag $=$ gneiss with amphibole, biotite and garnet

$\mathrm{Bio}=$ biotite

$\mathrm{LA}=$ coefficient Los Angeles

$\mathrm{MD}=$ coefficient Micro-Deval in the presence of water

For these purposes, we look at the gneisses of the structural unit of the Bénino-Togolese plain and the granites of the West African craton [10]. In total, have been analyzed thirty-two (32) samples taken (Figure 1) in the areas of Lomé, Kpalimé and Atakpamé, more precisely in the vicinities of Lilicopé (L1, L3, L5), Kpédji (Kp1 and Kp3), Gakocopé (Gk1 et Gk2), Badja (B1), Gléi (Gli2 and Gli3), Agbélouvé (Ag1, 2, Ag4 and Ag6), Glécopé (G12), Rodokpé (R 1, R 4, R 6) of Dapaong (St, St5, D1, Ng4, Ng6, Ng10, $\mathrm{Nd} 1, \mathrm{Nb} 1)$ and Kara (Km1, Ls1, Ls, 2, K1, F2). 


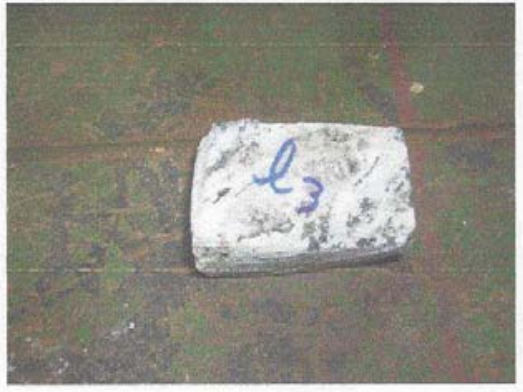

Figure 1. The sample prepared for the test.

The characteristics of the studied rocks are summarized in table 1 .

The essential intrinsic characteristics characterizing the samples are: the density, the mineralogical composition, porosity, the homogeneity [10]. The mechanical characteristics of the aggregates [11] consist of the resistance to abrasion using the Los Angeles machine and the resistance to attrition using the Micro-Deval machine [12, 13].

\subsection{The Rock Drillability Test}

The main question is to find out whether there exist possible correlations between the rock drillability test and the intrinsic and mechanical characteristics of the aggregates. The rock drillability test consists in measuring the depth created by the drill in a rock during a fixed time $(\mathrm{T})$, or in determining the time during which the drill leaves on the rock a print with a fixed depth.

The rock drilling test consisted in perforating the gneissic and granitic rocks using a drill of $6 \mathrm{~mm}$ of diameter with the speed of $550 \mathrm{rpm}$ under a load of $1 \mathrm{daN}$. After the time of perforation fixed at $10 \mathrm{~S}$, we measure the depth PF created by the drill in a sample of parallelepiped form.

To perform the perforation, a drill press CINCINNATI (Figure 2) to which was hung a dynamometer applying a drilling force of $1 \mathrm{daN}$ was used. On each sample, five perforations were made parallel to the layers of foliation and five perpendicularly to the foliation layers. By foliation we understand the entirety of the parallel plans according to which the new minerals crystallize.

After the perforation, a slide caliper was used to measure the depth of perforation obtained after $10 \mathrm{~s}$.

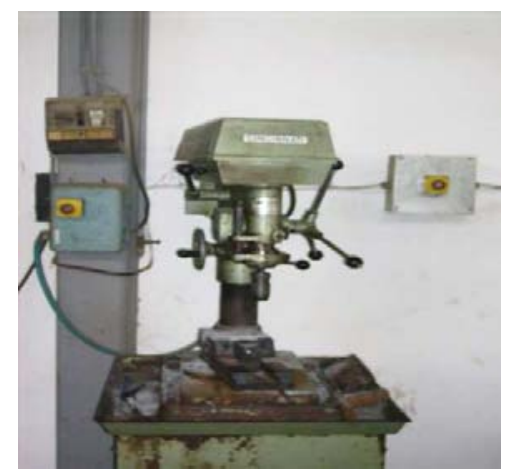

Figure 2. The CINCINNATI drilling machine.

\subsection{Data Processing}

Laboratory practices open a broad horizon of problems for which the use of statistical methods proves profitable and sometimes even indispensable. Among these methods, a paramount place is granted to the statistical study of the reciprocal connections between the variables. The mathematical tools used [14] in this field are primarily: correlation analysis and regression analysis.

The regression analysis enables to deduce an estimating equation which describes the functional nature of the relation between two variables, whereas the correlation analysis gives a measurement of the force of this relation.

In this study, the statistical analysis is used to determine the correlations between the rock drillability and other characteristics of the gneisses and granites, as well as the construction of models of rock drillability in correspondence with the mechanical properties of the rocks from which the gneisses and granites come.

\section{Results and Discussion}

\subsection{The Drillability Test Results}

The results of the tests made in accordance with the various directions in the foliation are presented on the figures 3 and 4 . Figure 5 presents the variation of the characteristics of the rocks according to the average depth determined by the layers of foliation (both parallel and perpendicular).

The clouds of points on the figures bellow show that from the analyzed samples it is impossible to obtain significant correlations, and to delineate regressions whatever the perforation method. This is explained by the large variety of petrographic types of the sampled gneiss and granites.

Nevertheless, it is possible to make certain important observations in relation to the average depth of perforation the speed of $550 \mathrm{rpm}$.

(a) Relating to the mineralogical composition

The data of perforation of the samples show that the depth of perforation depends on volume fraction of quartz in the rock. Thus, the rocks which depth of perforation is lower than $2 \mathrm{~mm}$ have a volume fraction of quartz $\geq 10 \%$.

There is a reduction of perforation depth with the increase of quartz fractions.

(b) Relating to the homogeneity

The analysis of the samples in relation to the homogeneity shows that the samples of depth perforation lower than 3,5 $\mathrm{mm}$ have a high homogeneity.

(c) Relating to the aggregate's resistance to shock (coefficient LA) and wear (coefficient MD)

One notices a marked tendency of the increase in the resistance of the aggregates when the depth of drilling rock decreases.

For the rocks of various types, the groups of dots are very dispersed. On the other hand, the analysis of tables 3 and 4 on the correlation of the foliated rocks and granites, shows strong intragroup correlations between the intrinsic properties 
(homogeneity and porosity), the mechanical properties (rock drillabilitty and LA, rock drillability MD, LA and MD) and between mineralogical and mechanical property (contain of quartz and LA, contain of quartz and MD, contain of quartz and rock drillability) for the average depth of perforation. This enables to determine: a) the homogeneity from the porosity, b) LA from the drilling property, c) MD starting from the rock drillability and d) the contain of quartz from the rock drillability.

\subsection{Analyses Correlation and Mathematical Model}

The analysis of correlation gives the measurement of the intensity of the dependence between two variables. This intensity is significant when the coefficient of correlation is close to the unit $(r \geq 0.5)$.

The mathematical functions allowing the determination of these characteristics per rock drilling test are indicated on the diagrams of figure 4 .
The depth of drilling rests on several factors and a multifactorial mathematical model based on the characteristics of the rock such as the Los Angeles coefficient, the Micro-Deval coefficient, the density, the homogeneity, the porosity and the contain of quartz and biotite, use monofactorial models. The study of the connection between several factors, entitled multifactorial regression, can be presented by the following equation:

$$
Y_{1,2, \ldots k}=f\left(x_{1}, x_{2} \ldots x_{k}\right)
$$

$\mathrm{Y}_{1,2}, \ldots \mathrm{Y}_{\mathrm{k}}$ : studied characteristic,

$\mathrm{x}_{1}, \mathrm{x}_{2}, \ldots . \mathrm{x}_{\mathrm{k}}$ : parameters of the model.

The best result for the totality of samples is obtained for the model that takes into account the Los Angeles coefficient (linear) and the quartz contents (power). The influence of other parameters is expressed in logarithmic form.

$$
P m=\alpha(L A)+\beta+\gamma\left(Q^{-0.817}\right)+\lambda \log (M D E)+\kappa \log (H)+\delta \log (d)+\varepsilon \log (B)+\xi \log (P)
$$

Pm: average depth of perforation ( $\mathrm{mm}$ )

LA: coefficient Los Angeles

$\mathrm{Q}$ : content of quartz (\% volume)

MDW: coefficient Micro Deval in the presence of water

$\mathrm{H}$ : homogeneity

D: density

B: contain of biotite ( $\%$ volume)

P: porosity

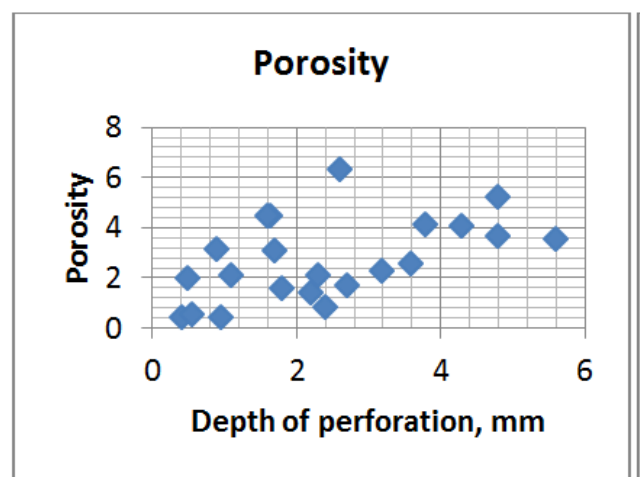

(a)

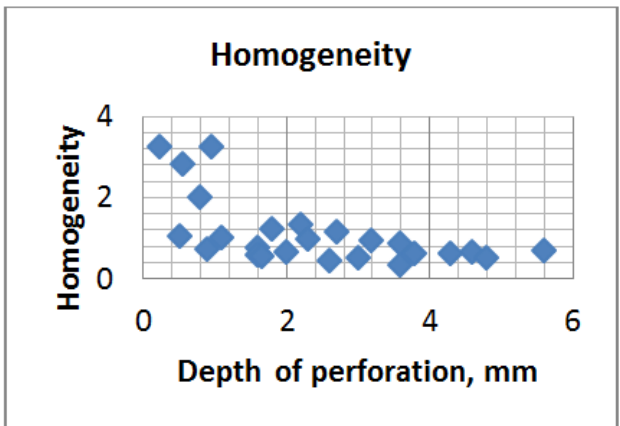

(c)

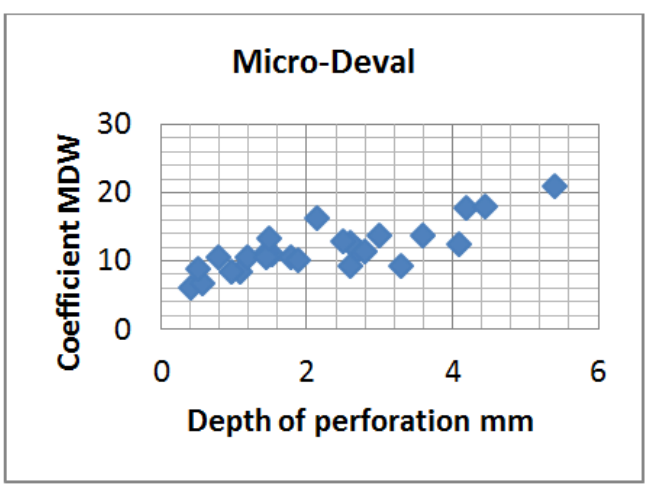

(b)

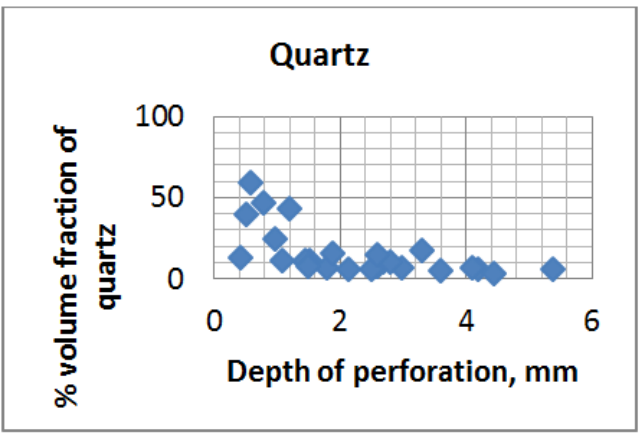

(d) 


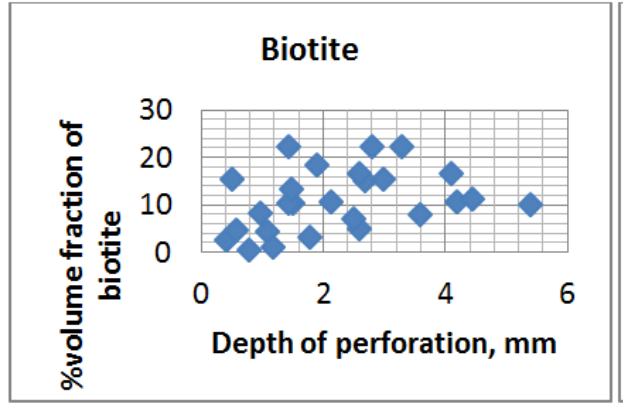

(e)

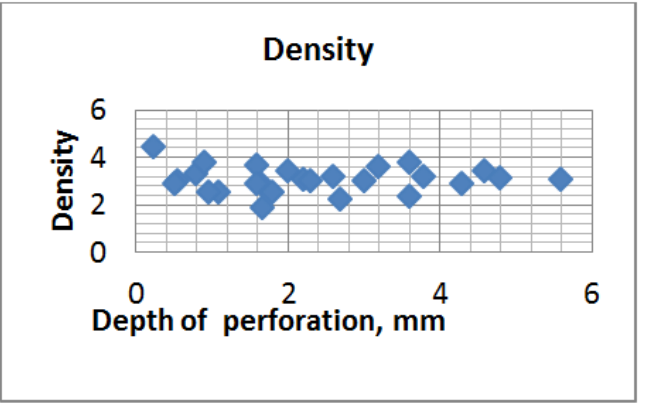

(f)

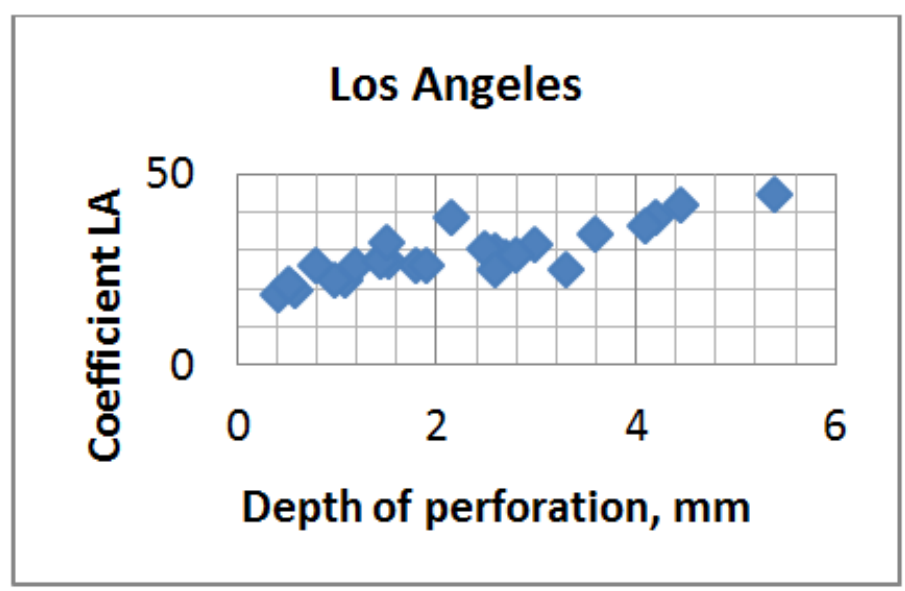

(g)

Figure 3. Variation of the characteristics of the rocks according to the rock drillability Pf in the plan of foliation, speed $550 \mathrm{rpm}$.

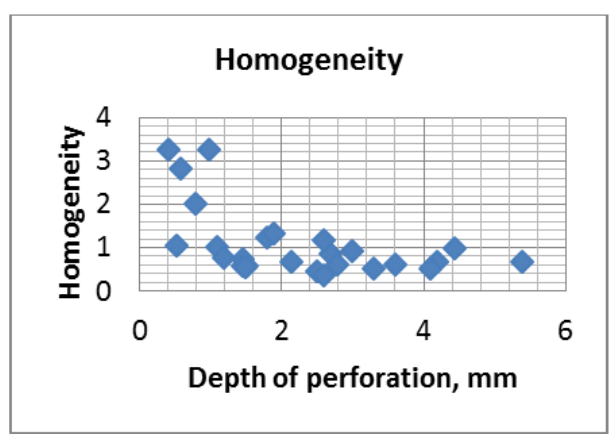

(a)

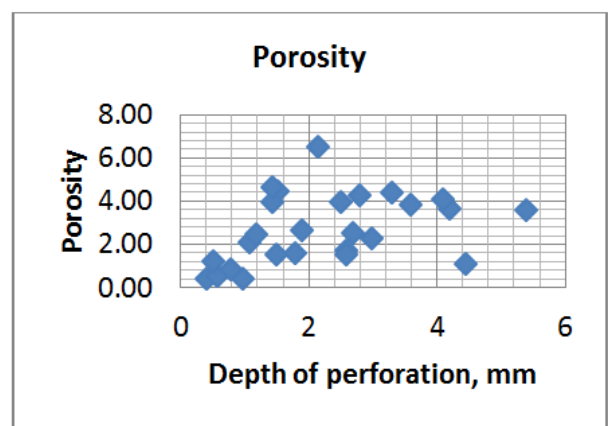

(b)

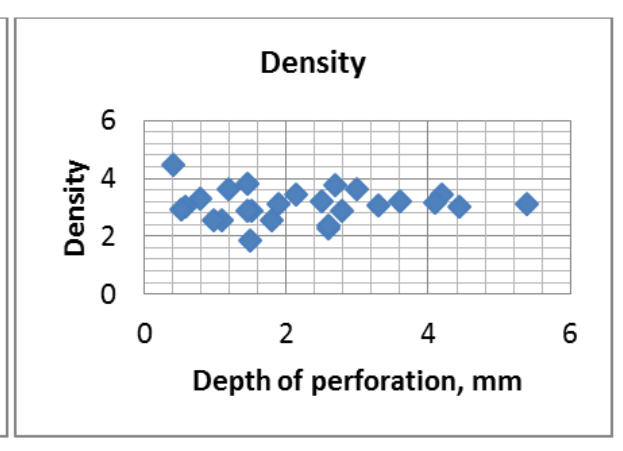

(b)

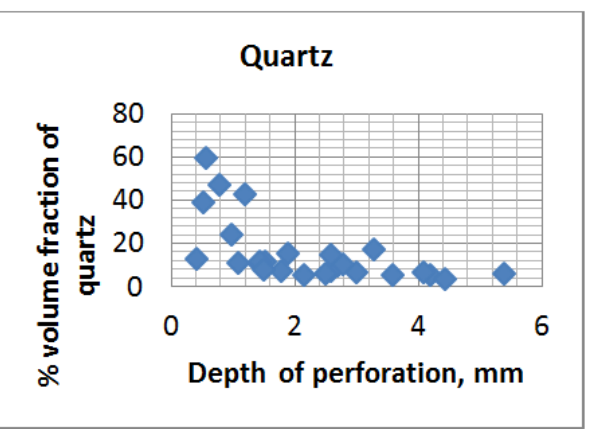

(d) 


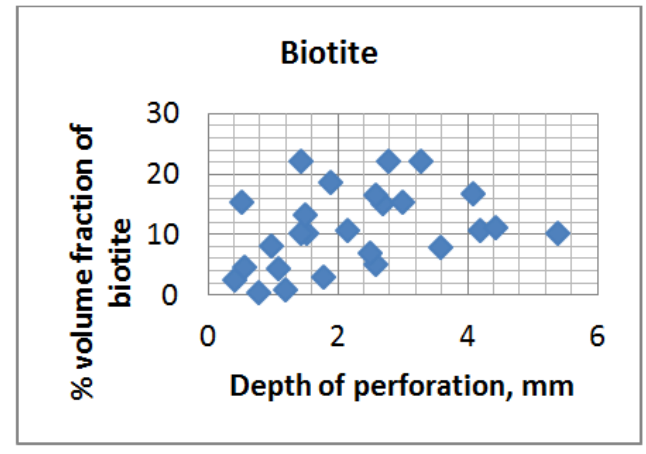

(e)

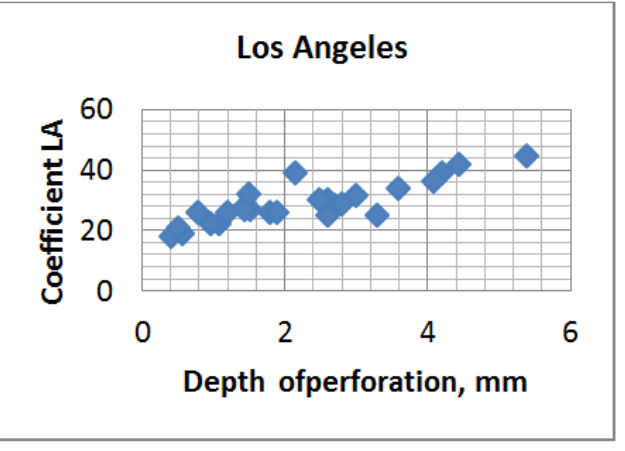

(f)

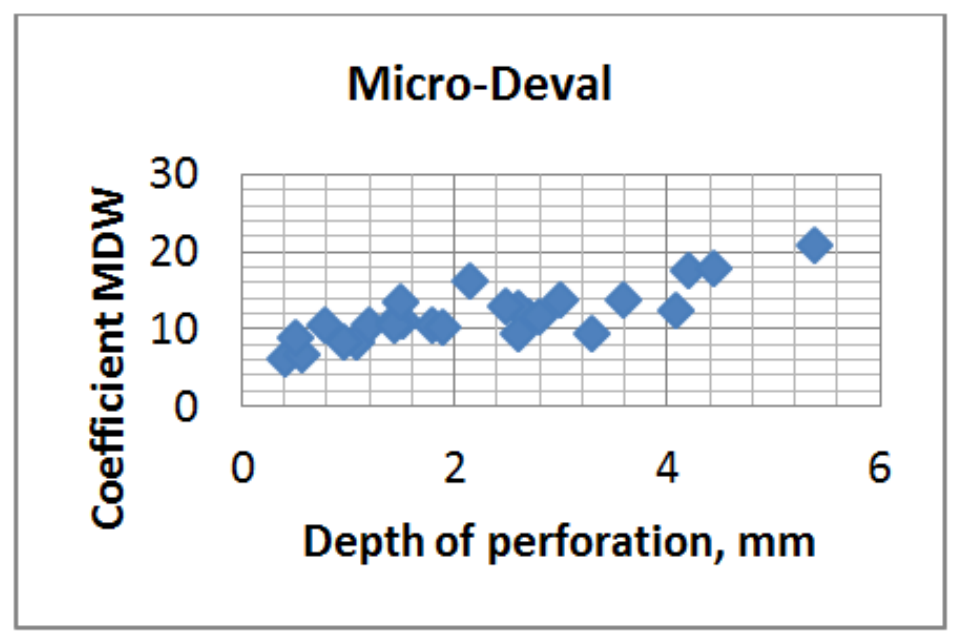

(g)

Figure 4. Variation of the characteristics of the rocks according to the rock drillabilityPpf perpendicular to the plan of foliation, speed 550 rpm.

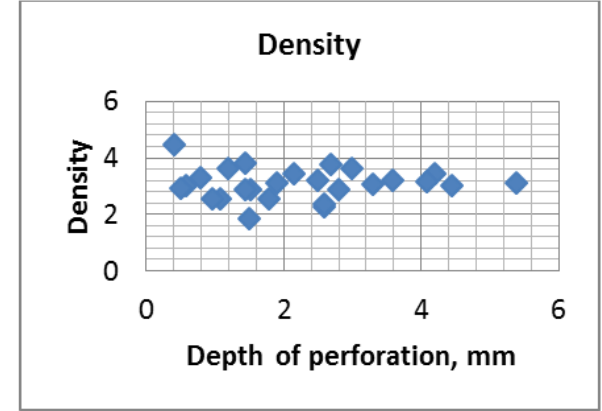

(a)

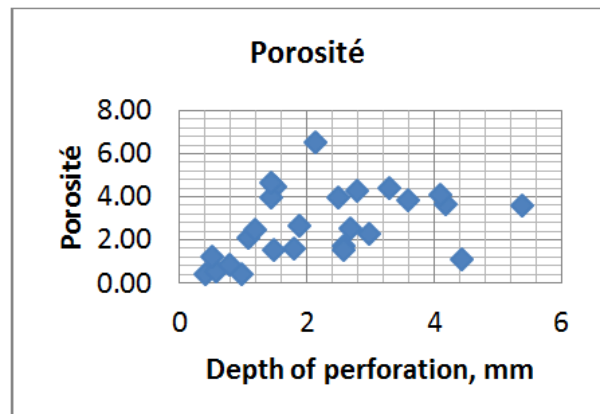

(c)

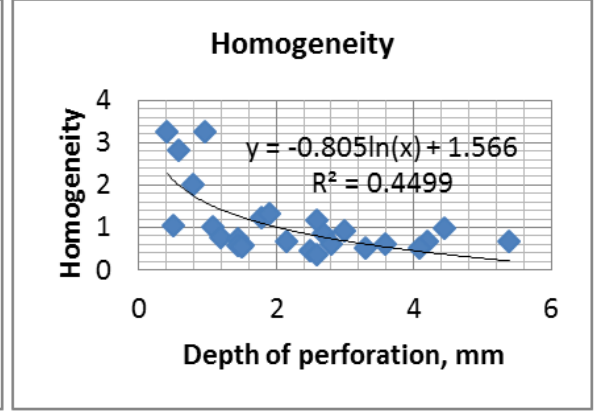

(b)

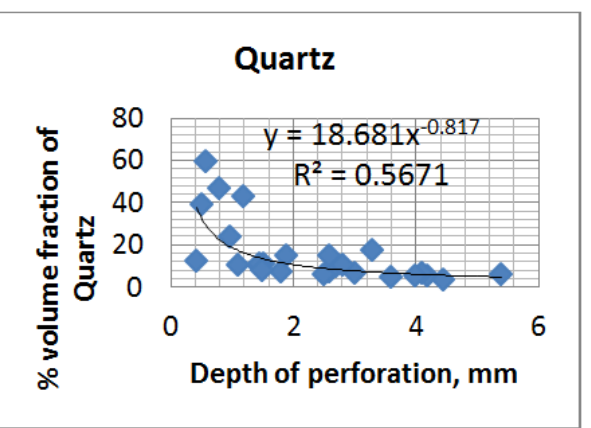

(d) 


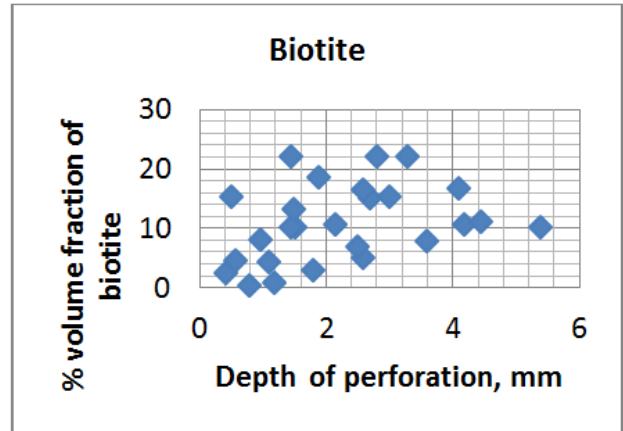

(e)

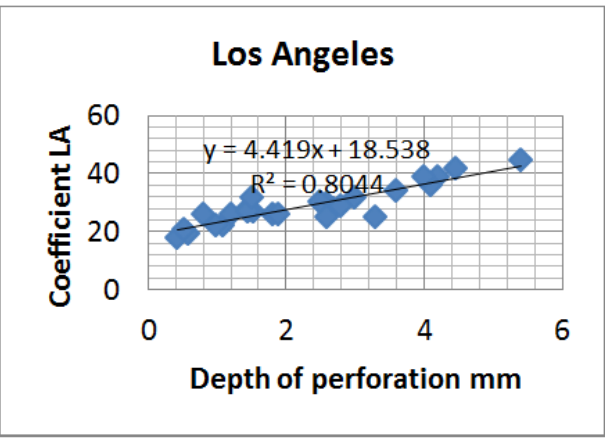

(f)

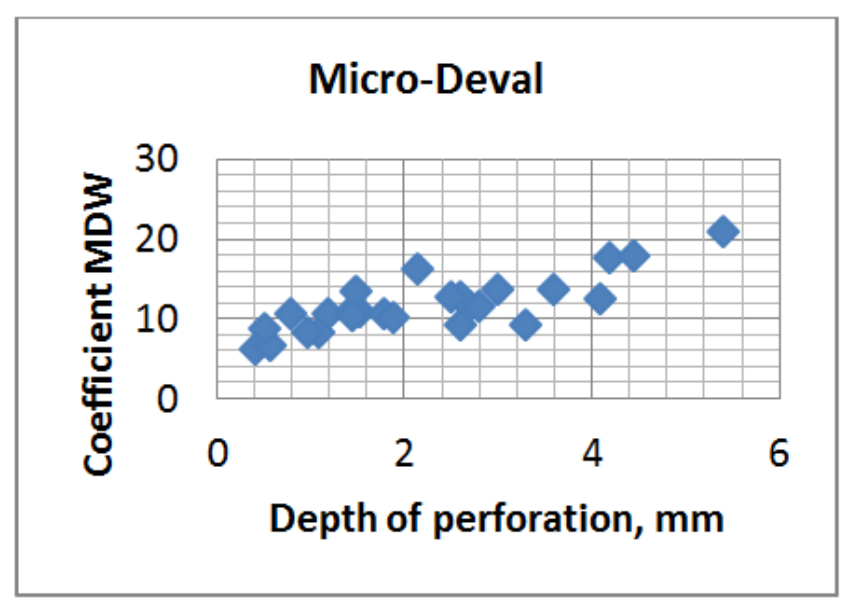

(g)

Figure 5. Variation of the characteristics of the rocks according to average rock drillability Pm, speed $550 \mathrm{rpm}$.

Table 2. Coefficient of correlation of the foliated characteristics of the gneisses and granites at the speed $550 \mathrm{rpm}$.

\begin{tabular}{|c|c|c|c|c|c|c|c|c|c|c|}
\hline & Pf & Ppf & Pm & LA & MDW & Density & Homogeneity & Porosity & Quartz & Biotite \\
\hline Pf & 1.0000 & 0.6552 & 0.9082 & 0.7741 & 0.7167 & 0.0775 & -0.5949 & 0.6591 & -0.5404 & 0.3393 \\
\hline $\mathrm{Pm}$ & 0.9082 & 0.9046 & 1.0000 & 0.8868 & 0.8298 & 0.0578 & -0.5823 & 0.4808 & -0.6094 & 0.3202 \\
\hline LA & 0.7741 & 0.8454 & 0.8868 & 1.0000 & 0.9740 & -0.0092 & -0.5461 & 0.4354 & -0.5525 & 0.1408 \\
\hline MDW & 0.7167 & .07927 & 0.8298 & 0.9740 & 1.0000 & 0.0002 & -0.5086 & 0.3683 & -0.5011 & 0.0644 \\
\hline Density & 0.0775 & 0.0394 & 0.0578 & -0.0072 & 0.0002 & 1.0000 & 0.1198 & 0.1405 & 0.0475 & 0.0232 \\
\hline Homogeneity & -0.5949 & -0.4538 & -0.5823 & -0.5461 & -0.5086 & 0.1198 & 1.0000 & -0.6199 & 0.4844 & -0.4559 \\
\hline Porosity & 0.6591 & 0.2617 & 0.4808 & 0.4354 & 0.3683 & 0.1405 & -0.6179 & 1.0000 & -0.3962 & 0.5041 \\
\hline Quartz & -0.5404 & -0.5618 & -0.5525 & -0.5525 & -0.5011 & 0.0475 & 0.4844 & -0.3962 & 1.0000 & -0.2734 \\
\hline Biotite & 0.3393 & 0.2568 & 0.1408 & 0.1408 & 0.0644 & 0.0232 & -0.4559 & 0.5041 & -0.2734 & 1.0000 \\
\hline
\end{tabular}

Table 3. Coefficients of probability of the foliated gneisses and granites at the speed $550 \mathrm{rpm}$.

\begin{tabular}{|c|c|c|c|c|c|c|c|c|c|c|}
\hline & Pf & Ppf & Pm & LA & MDW & Density & Homogeneity & Porosity & Quartz & Biotite \\
\hline $\mathrm{Pf}$ & 1.0000 & 0.0002 & 0.0000 & 0.0000 & 0.0000 & 0.7009 & 0.0011 & 0.0002 & 0.0036 & 0.0833 \\
\hline Ppf & 0.0002 & 1.0000 & 0.0000 & 0.0000 & 0.0000 & 0.8453 & 0.0194 & 0.1873 & 0.0023 & 0.1959 \\
\hline $\mathrm{Pm}$ & 0.0000 & 0.0000 & 1.0000 & 0.0000 & 0.0000 & 0.7747 & 0.0014 & 0.0111 & 0.0007 & 0.1034 \\
\hline LA & 0.0000 & 0.0000 & 0.0000 & 1.0000 & 0.0000 & 0.9715 & 0.0032 & 0.0232 & 0.0028 & 0.4835 \\
\hline MDW & 0.0000 & 0.0000 & 0.0000 & 0.0000 & 1.0000 & 0.9991 & 0.0067 & 0.0587 & 0.0078 & 0.7498 \\
\hline Density & 0.7009 & 0.8453 & 0.7049 & 0.9715 & 0.9991 & 1.0000 & 0.5518 & 0.4847 & 0.8141 & 0.9086 \\
\hline Homogeneity & 0.0011 & 0.0174 & 0.0014 & 0.0032 & 0.0067 & 0.5518 & 1.0000 & 0.0006 & 0.0104 & 0.0169 \\
\hline Porosity & 0.0002 & 0.1873 & 0.0111 & 0.0232 & 0.0587 & 0.4847 & 0.0006 & 1.0000 & 0.0408 & 0.0073 \\
\hline Quartz & 0.0036 & 0.0023 & 0.0007 & 0.0028 & 0.0078 & 0.7141 & 0.0104 & 0.0408 & 1.0000 & 0.1676 \\
\hline Biotite & 0.0833 & 0.1959 & 0.1034 & 0.4835 & 0.6498 & 0.9086 & 0.0169 & 0.0017 & 0.1676 & 1.0000 \\
\hline
\end{tabular}

Ppf depth of perforation in the perpendicular plan of foliation

$\mathrm{Pf}=$ dept of perforation to the plan of foliation

$\mathrm{Pm}=$ depth of average perforation

LA $=$ coefficient Los Angeles

$\mathrm{MD}=$ coefficient Micro-Deval in the presence of water 
The matrix representation of the model is given by equation 3 .

$$
\left[\begin{array}{c}
P m_{1} \\
P m_{2} \\
\vdots \\
P m_{n-1} \\
P m_{n}
\end{array}\right]=\left[\begin{array}{cccccccc}
L A_{1} & 1 & Q_{1}^{-0.817} & \log M D E_{1} & \log H_{1} & \log d_{1} & \log B_{1} & \log P_{1} \\
L A_{2} & 1 & Q_{2}^{-0.817} & \log M D E_{2} & \log H_{2} & \log d_{2} & \log B_{2} & \log P_{2} \\
\vdots & \vdots \ldots & \vdots & \vdots & \vdots & \vdots & \vdots & \vdots \\
L A_{n-1} & 1 & Q_{n-1}^{-0.817} & \log M D E_{n-1} & \log H_{n-1} & \log d_{n-1} & \log B_{n-1} & \log P_{n-1} \\
L A_{n} & 1 & Q_{n}^{-0.817} & \log M D E_{n} & \log H_{n} & \log d_{n} & \log B_{n} & \log P_{n}
\end{array}\right] \times\left[\begin{array}{c}
\alpha \\
\beta \\
\gamma \\
\lambda \\
\kappa \\
\varepsilon \\
\xi
\end{array}\right]
$$

This system is equivalent to the following:

$$
E_{1}=M_{1} \times C_{1}
$$

E1: - matrix of the Pm coefficient

M1: intermediary matrix. This matrix is formed by the values of the mineralogical composition, the structure, the homogeneity and the density, corresponding to the samples for which one wishes to identify Pm

$\mathrm{C} 1$ : coefficients of the model

The coefficients of the model are determined using the following equation:

$$
C_{1}=M^{-1} \times E_{1}
$$

The system of equation (Eq. 3) being overdetermined, the criterion of minimization selected is that of least squares. The resolution of this system of equations is developed in the Matlab program [14] with the functions: pinv and lsqr on figure 6.

Values of the coefficients obtained:

$\alpha=0.2322 ; \beta=-0.84628 ; \gamma=0.89016 ; \lambda=-1.5602 ; \kappa=-0.4385$; $\delta=-0.095 ; \varepsilon=0.1827 ; \zeta=-0.263$

Once these coefficients are calculated, one can determine the Pm coefficient using the following matrix product:

$$
L A_{1}=M_{1} \times C_{1}
$$

Figure 6 represents the simultaneous layout of the values of average perforation depth measured and identified according to the model.

The gaps noticed in relation to the measured data are linked to the diversity of the types of studied rocks. When one applies this same model to the rocks of evident foliation texture or equate, one obtains more reliable results (figure 7) with the values of the obtained coefficients:

$\alpha=0.241 ; \beta=-1.6628 ; \gamma=3.2627 ; \lambda=-1.5236 ; \kappa=0.11 ; \delta=-$ $0.034 ; \varepsilon=0.1366 ; \zeta=-0.0472$.

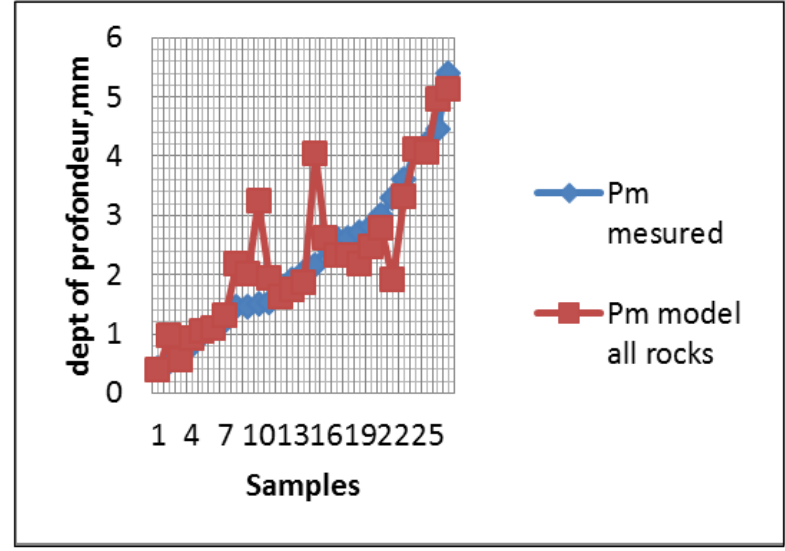

Figure 6. Average depths of perforation Pm measured and identified according to the model.

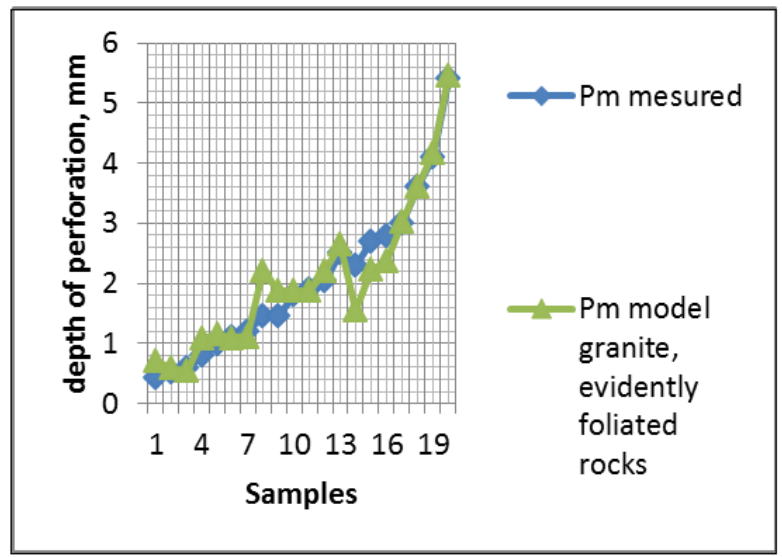

Figure 7. Average depths of perforation measured and identified according to the model Pm for the evidently foliated gneisses and granites.

The simulation of the model applied to the six (06) granite and gneiss samples with foliated structure gave the results presented in Table 4.

Table 4. Simulation results.

\begin{tabular}{llll}
\hline Samples & Depth of perforation Pm according to model, $\mathbf{~ m m}$ & Depth of perforation Pm real, $\mathbf{m m}$ & Gap between real and model,\% \\
\hline $\mathrm{Nb} 1$ & 0.70 & 0.68 & 2.94 \\
$\mathrm{Nd} 1$ & 0.71 & 0.70 & 1.43 \\
$\mathrm{~F} 2$ & 1.38 & 1.40 & -1.43 \\
$\mathrm{Ng} 6$ & 1.80 & 1.80 & 0.00 \\
$\mathrm{Ng} 10$ & 1.94 & 1.90 & 2.11 \\
$\mathrm{St} 5$ & 2.00 & 2.10 & -4.76 \\
\hline
\end{tabular}




\section{Conclusion}

The Togolese gneisses and granite were characterised by two types of properties: intrinsic with the porosity, the homogeneity, the mineralogical composition, the density, and mechanical with the Los Angeles coefficient, the MicroDeval coefficient, and the rock drillability.

For the intrinsic properties, it is necessary to note the significant correlation between the homogeneity and the porosity of the rocks with evident foliated texture. For the mechanical properties, there is a significant correlation between the drilling property and the Los Angeles and Micro-Deval coefficients and finally between the Los Angeles coefficient and the Micro-Deval coefficient.

The significant correlations were observed between the rock drillability, the Los Angeles coefficient and the MicroDeval coefficient and the contain of quartz.

The analysis of the regressions was permitted to construct mathematical models for estimation the intrinsic and mechanical properties the gneisses with evident foliated texture and granites by the rock drilling test.

The multifactorial analysis confirms the interdependence between the rock dryllability and the properties of the rocks.

\section{References}

[1] Arnold S. Marfunin, Composition, structure, and properties of mineral matter, Springer, Berlin, (2012), 551.

[2] Walter Borchardt-Ott «Cristallography», Springer, Berlin, (2011), 355 .

[3] M. P. Jones, Applied mineralogie a quantitative approach, Springer, Netterlands, (2009) 260.

[4] Hianyang Zhang, Aspect of rock perméability, SP Heigher Education Press, In frontiers of structural and Civil Engineering, Vol. 7, (2013) 102-116.
[5] Pachoukova Irina, Ayité Dany Y. M. X., Jonhson Ampah Kodjo Christophe, Caractérisation géotechnique des calcaires de Tabligbo: Bassin sédimentaire côtier du Togo, Rev. Ivoir. Sci. Technol., (2015), 25, 71-79.

[6] Dahl Filip, Bruland Amund, Jakobsen Pål Drevland, Nilsen Bjørn, Grøv Eivind Classification of properties influencing the drillability of rocks, based on the NTNU/SINTEF test method, Tunnelling and Underground Space Technology. volum 28,.( 2012), 22-30.

[7] T. N. Singh, A. R. Gupta and R. Sain, A comparative analysis of congnitive systems for the prediction of drillability of rocks and wear factor, Geotechnical and Geological Engineering Springer, (2006), 24:299-312.

[8] Mohammad Ataei, Resa Kakaie, Mehdi Ghavidel, Omid Saeidi, Drilling rate prediction of an open pit mine using the rock mass drillability index, International Journal of Rock Mechanics and Mining Sciences, Elsevier Science, (2015) 73:130-138.

[9] A. Taheri, Q. Qao, E. Chanda, Drilling penetration rate estimation using Rock Drillability Caracterisation Index, Spriger India, Series D, (2016), 97(2):159-170.

[10] Irina Pachoukova, Modélisation de la résistance des granites et des gneiss du Togo, doctorat unique en sciences de l'ingénieu, Lomé, Togor (2008).

[11] Pierre HABIB «Génie géotechnique: Application de la mécanique des sols et des roches», Elipses, (1997), 222.

[12] Norme française: NFP18-573 «Granulats - Essai Los Angeles»(1990).

[13] Norme française NFP 18-572 «Granulats, essai d'usure MicroDeval» (1990).

[14] Sergio H. Faria, Kolumban Hutte, Continium description of granular materals, Springer, Berlin, (2010), 550.

[15] Mocthari M., Mesbah A., Apprendre et maîtriser MATLAB, Spriger-Verlag Berlin Heidelber,(1997), pp:37-83, 696. 